\title{
Mielite Extensa como Manifestação de Neuroborreliose
}

\section{Extensive Myelitis as a Manifestation of Neuroborreliosis}

Ana BRÁS $\square^{1}$, Nuno MARQUES ${ }^{2}$, Beatriz SANTIAGO ${ }^{1}$, Anabela MATOS ${ }^{1}$, Fradique MOREIRA ${ }^{1}$

Acta Med Port 2016 Sep;29(9):564-566 - http://dx.doi.org/10.20344/amp.7400

RESUMO

As manifestações neurológicas na doença de Lyme ocorrem em 3\% - 12\% dos doentes, sendo a forma de apresentação mais comum a meningorradiculite. Outros sintomas de envolvimento do sistema nervoso central, como encefalomielite ou mielite são raros (<5\%). Descreve-se um caso clínico de um homem de 66 anos com uma mielite transversa extensa, de instalação subaguda, secundária a infeção por Borrelia burgdorferi. O doente foi submetido a terapêutica antibiótica dirigida, com uma boa evolução clínica. A raridade na forma de apresentação clínica e imagiológica deste caso, tendo como base uma doença infecciosa tratável, destaca a importância da sua inclusão no diagnóstico diferencial da mielite transversa longitudinalmente extensa.

Palavras-chave: Mielite Transversa; Neuroborreliose de Lyme.

\section{ABSTRACT}

Neurological manifestations of Lyme disease are reported in 3\% - 12\% of patients, with the most common form of presentation being meningoradiculitis. Other symptoms involving the central nervous system, such as myelitis or encephalitis, are rare $(<5 \%)$. We report a case of a 66-year-old male, with a subacute extensive transverse myelitis, secondary to Borrelia burgdorferi infection. The patient underwent antibiotic therapy filed for neuroborreliosis with a good clinical outcome. The rareness in clinical symptoms and imaging presentation, based on a treatable infectious disease, highlights the importance of the inclusion of neuroborreliosis in the differential diagnosis of longitudinally extensive transverse myelitis.

Keywords: Lyme Neuroborreliosis; Myelitis, Transverse.

\section{INTRODUÇÃO}

A doença de Lyme é uma infeção multissistémica causada pela picada da carraça (espécie Ixodes ricinus) infetada pela espiroqueta Borrelia burgdorferi sensu latu. A picada provoca uma resposta inflamatória local, caracterizada por uma erupção cutânea, designada por eritema migrans. Apenas em $20 \%$ - 30\% dos casos é relatada a presença do eritema migrans. ${ }^{1}$ A disseminação sistémica é acompanhada de sintomas pseudogripais, ${ }^{2}$ podendo posteriormente ser acompanhada de envolvimento do sistema nervoso (síndrome Garin-Bujadoux-Bannwarth) ${ }^{3}$ em 10\% - 15\%, articular em $10 \%$ e cardíaco em $1 \%-2 \%$ dos casos. ${ }^{4}$

Os sintomas neurológicos ocorrem geralmente entre a primeira e a décima segunda semana após picada da carraça infetada. ${ }^{1,5}$

As manifestações neurológicas na doença de Lyme precoce (primeiros seis meses) ocorrem em $3 \%-12 \%$ dos doentes, sendo a meningorradiculite a forma de apresentação mais comum, seguida da meningite linfocítica. Outros sintomas de envolvimento precoce do sistema nervoso central, como encefalomielite e mielite são raros $(<5 \%){ }^{6}$ As formas de mielite relatadas na literatura são caracterizadas pelo envolvimento medular transverso e longitudinal. ${ }^{7,8}$

\section{CASO CLÍNICO}

Apresentamos o caso clínico de um homem de 66 anos de idade, raça caucasiana, com um quadro subagudo (duas semanas de evolução) e progressivo de fraqueza dos membros inferiores associado a retenção urinária e fecal. O doente tinha insuficiência cardíaca congestiva, fibrilhação auricular hipocoagulada, e múltiplos fatores de risco vascular: obesidade (IMC $31 \mathrm{~kg} / \mathrm{m}^{2}$ ), hipertensão arterial e diabetes mellitus tipo 2 não insulino-tratada. Era previamente autónomo e residente em meio rural, sem estadias no estrangeiro. Não apresentava história de vacinação recente nem de infeções, picada por artrópodes ou lesões cutâneas compatíveis com eritema migrans. Negava dor ou parestesias sugestivas de envolvimento radicular.

$\mathrm{Na}$ avaliação neurológica não havia alteração ao exame das funções nervosas superiores (MoCA 27/30) e apresentava surdez neurossensorial à direita, sem alterações ao exame dos restantes pares cranianos. O exame motor revelou paraparésia assimétrica, com padrão de distribuição de fraqueza de tipo piramidal (G2 no membro inferior direito e G3 proximal/G4 distal no membro inferior esquerdo), hipotonia e hiporreflexia miotática dos membros inferiores e cutâneo-plantares em extensão bilateralmente. Apresentava um nível de sensibilidade álgica e palestésica em D6 e reflexos cutâneo-abdominais ausentes. Na revisão de aparelhos e sistemas, salientava-se retenção urinária e ausência de eritema cutâneo.

A ressonância magnética (RM) medular evidenciou extenso hipersinal medular em T2, desde o nível D4-D5 até ao cone medular (Fig.1) e envolvimento transverso (Fig.2) compatíveis com mielite transversa longitudinalmente extensa. A RM craneoencefálica (CE) não mostrou realce leptomeníngeo e evidenciou Schwannoma vestibular direito.

1. Serviço de Neurologia. Centro Hospitalar e Universitário de Coimbra. Coimbra. Portugal.

2. Serviço de Doenças Infecciosas. Centro Hospitalar e Universitário de Coimbra. Coimbra. Portugal.

$\square$ Autor correspondente: Ana Brás. acatbras4@hotmail.com

Recebido: 14 de janeiro de 2016 - Aceite: 27 de abril de 2016 | Copyright @ Ordem dos Médicos 2016 


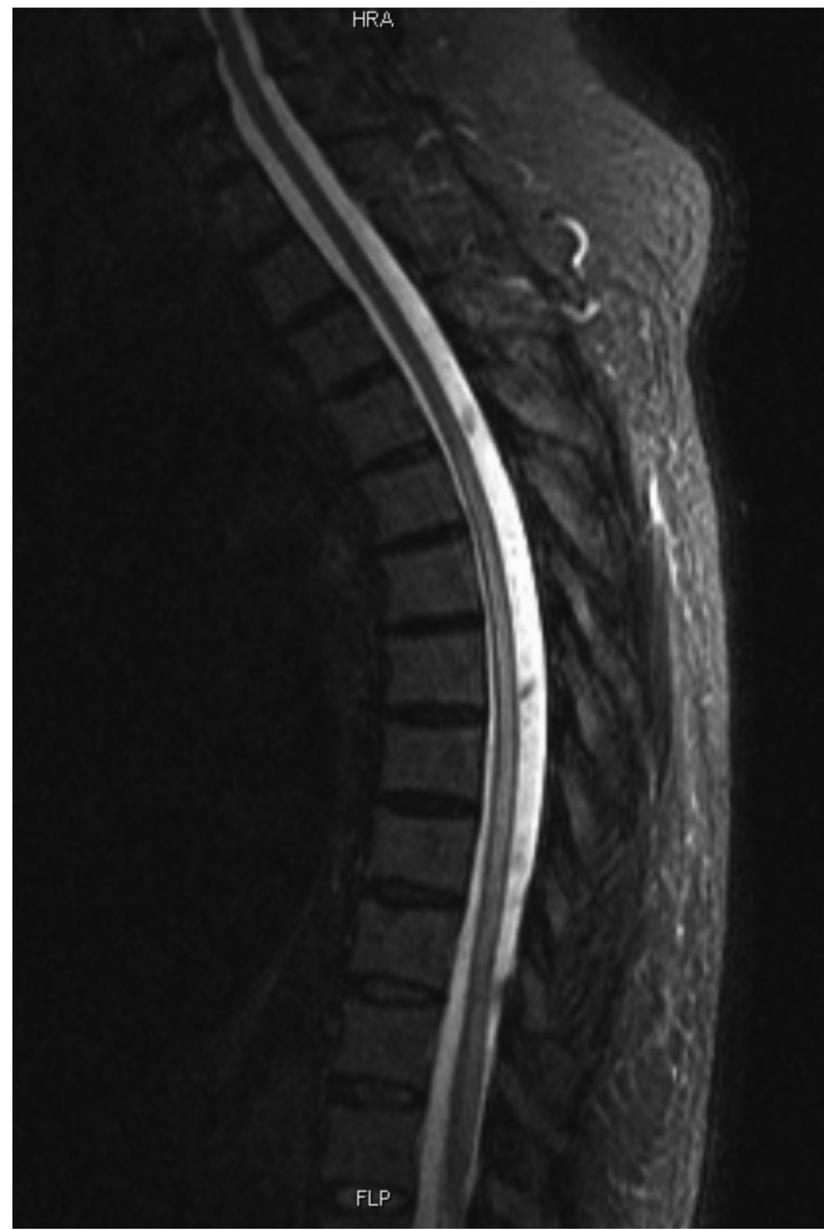

Figura 1 - RM-Medular (T2) revela extenso hipersinal desde o nível D4-D5 até ao cone medular
Não foi identificada qualquer alteração analítica nas rotinas laboratoriais gerais.

O estudo citoquímico do LCR revelou pleocitose linfocítica (40 leucócitos, 100\% mononucleares) e hiperproteinorraquia (120 $\mathrm{mg} / \mathrm{dl})$.

A serologia para Borrelia spp., por técnica de imunofluorescência indireta, foi positiva no soro e no LCR com a detecção de IgM em ambos os líquidos biológicos. Foram excluídas infecções por VHS, CMV, VEB, VIH, VLTH, VHA, VHB, VHC, Treponema pallidum, Brucella spp. e Mycobacterium tuberculosis. A infeção por Borrelia spp. foi confirmada laboratorialmente por técnicas de biologia molecular no LCR (PCR). A PCR no LCR para vários vírus (CMV, VEB, VHS-1, VHS-2, VVZ, Enterovírus) foi negativa.

A pesquisa de Bandas Oligoclonais revelou-se positiva: $\operatorname{LCR}(+++)$ / Soro(+).

$\mathrm{O}$ restante estudo complementar microbiológico, inflamatório/autoimune (anticorpos anti-cANCA, anti-pANCA, anti-ds-DNA, anti-SSA60, anti-SS13, anti-Sm, anti-RNP, anti-Scl70, anti-JO1, anti-nucleares, anti-citoplasmáticos, anti-fosfolipídico, anti-AQ4) e paraneoplásico (anticorpos antineuronais e marcadores tumorais) mostrou-se negativo.

Pela hipótese de mielite de causa inflamatória iniciou terapêutica com metilprednisolona na dose de $1 \mathrm{~g} / \mathrm{dia}$ que efetuou durante três dias. Nas primeiras 48 horas foi introduzida antibioterapia endovenosa com ceftriaxone $2 \mathrm{~g} / \mathrm{dia}$, que manteve durante 28 dias, e antivírico (aciclovir 10 mg/ $\mathrm{kg} / \mathrm{dia}$ ) suspenso à data do estudo confirmatório.

O estudo de condução nervosa motora e sensitiva e exame muscular com elétrodo-agulha não revelou sinais de envolvimento radicular ou de polineuropatia sensitiva ou motora.

O doente apresentou uma boa resposta ao tratamento

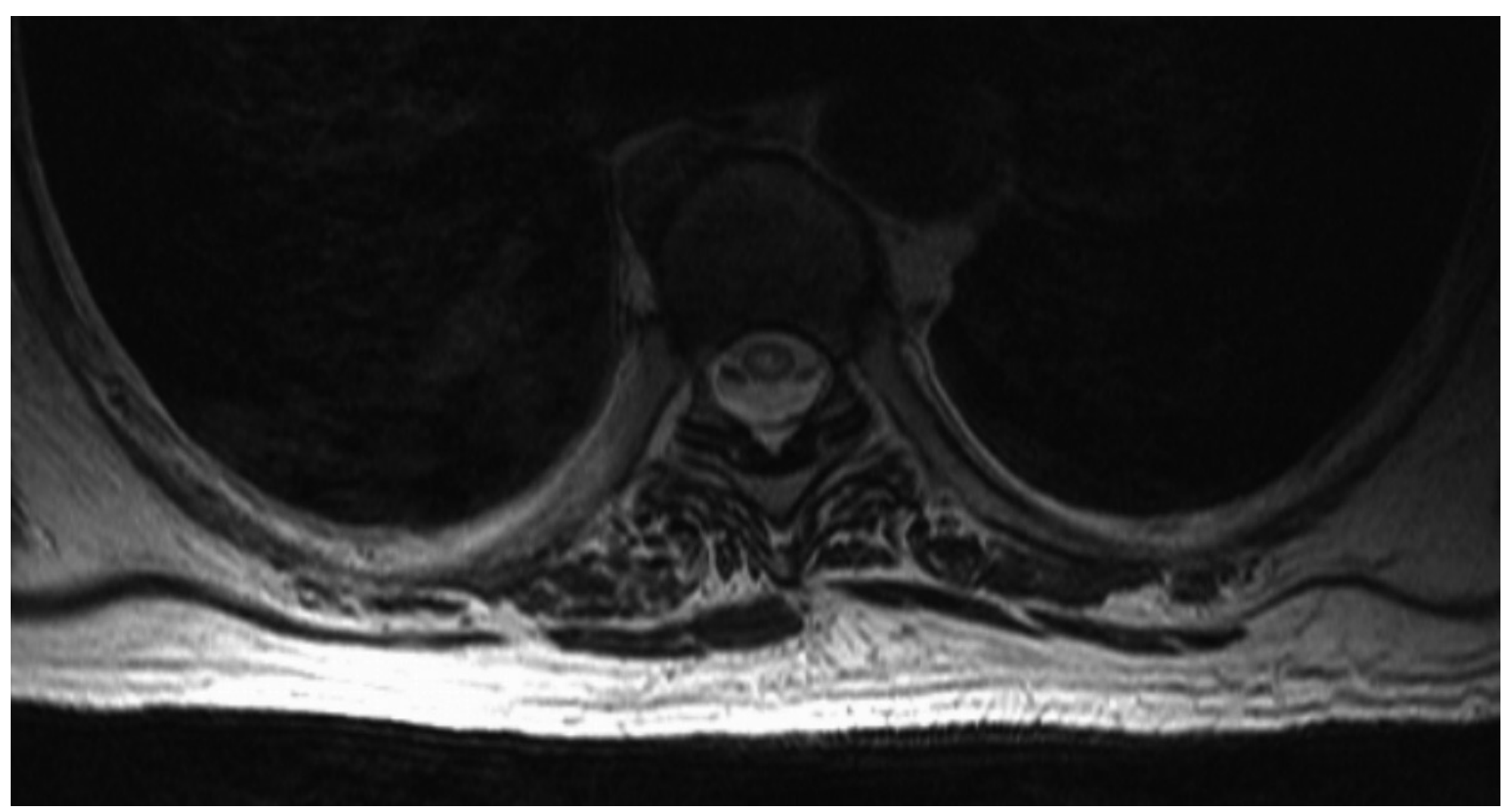

Figura 2 - RM-Medular (T2) ao nível de D7 mostra envolvimento medular transverso superior a 2/3 
realizado e, ao $28^{\circ}$ dia de antibioterapia, a marcha era possível com apoio sendo posteriormente orientado para centro de medicina física e reabilitação. Ao terceiro mês pós tratamento apresentava uma paraparésia assimétrica espástica, de predomínio esquerdo e algaliação crónica por retenção urinária. A RM-medular e o estudo electromiográfico de controlo mostraram-se sobreponíveis. O estudo citoquímico do LCR revelou uma redução da pleocitose e proteinorraquia (5 leucócitos; $88 \mathrm{mg} / \mathrm{dL}$ ). A PCR no LCR para Borrelia spp. foi negativa. Não se assistiu à conversão serológica no soro e no LCR (IgG negativa para Borrelia spp.).

\section{DISCUSSÃO}

A mielite é uma entidade rara e o diagnóstico baseia-se na apresentação clínica e imagiológica, complementada pelo estudo de líquido cefalorraquidiano (LCR). O diagnóstico diferencial implica pesquisa de causas infecciosas, parainfecciosas, desmielinizantes e inflamatórias (autoimunes ou idiopáticas). ${ }^{9}$

Perante uma mielite longitudinalmente extensa, como neste caso, pressupõe-se a exclusão de doenças do espectro da neuromielite óptica através da negatividade dos anticorpos anti-AQ4 (sensibilidade de 63\% por imunofluorescência indireta) e ausência de disseminação no espaço de lesões core (ex. nevrite óptica, síndrome área postrema ou diencefálico). ${ }^{10}$ As causas autoimunes foram excluídas pela ausência de manifestações sistémicas e negatividade do estudo autoimune dirigido.

A neuroborreliose como causa de mielite é rara, e está associada a manifestações clínicas graves, particularmente no grau de fraqueza muscular e de disfunção urinária. ${ }^{11,12}$ A detecção e o tratamento precoce são fundamentais na prevenção da progressão da doença. ${ }^{8,13,14}$ Assim como neste caso clínico, há relatos de infeção em que não existem sintomas sistémicos iniciais associados. ${ }^{11}$

Os sintomas neurológicos, a pleocitose linfocítica do LCR e a produção intratecal de anticorpos Borrelia spp. específicos $^{1,6}$ fazem parte dos critérios de neuroborreliose. A pesquisa de PCR no LCR é útil quando a duração inicial dos sintomas neurológicos é inferior a seis semanas, período este em que a produção intratecal de anticorpos específicos para Borrelia poderá ser negativa. ${ }^{1}$ Nestas circunstâncias, a identificação de ADN de Borrelia spp. por PCR no LCR tem uma especificidade de $98 \%-100 \%,{ }^{1}$ o que permitiu afirmar o diagnóstico definitivo de neuroborreliose no caso clínico apresentado.

As serologias por imunofluorescência indireta no soro/ LCR na neuroborreliose precoce têm sensibilidade de $70 \%$ - 90\%, mas especificidade baixa. ${ }^{1}$ Por outro lado, a seroconversão lgG é rara e muito variável, não sendo relevante para a confirmação do diagnóstico. ${ }^{15}$

No presente caso, o diagnóstico de Mielite por Borrelia spp. é corroborado pelo exame citoquímico, serológico e pela detecção de ADN da Borrelia spp. por PCR no LCR. A resposta ao tratamento e a evolução clínica e laboratorial suportam este diagnóstico.

A raridade na forma de apresentação clínica e imagiológica de doença infecciosa tratável, evidencia a importância da sua inclusão no diagnóstico diferencial da mielite transversa longitudinalmente extensa.

\section{OBSERVAÇÕES}

Este caso clínico foi apresentado como poster no Congresso da Sociedade Portuguesa de Neurologia que decorreu em Lisboa, no Sana Hotel entre 11 e 14 de novembro de 2015.

\section{CONFLITOS DE INTERESSE}

Os autores declaram não terem qualquer conflito de interesse relativamente ao presente artigo.

\section{FONTES DE FINANCIAMENTO}

Os autores declaram não ter recebido subsídios ou bolsas para a elaboração do artigo.

9. Jacob A, Weinshenker BG. An approach to the diagnosis of acute transverse myelitis. Semin Neurol. 2008;28:105-20.

10. Wingerchuk DM, Banwell B, Bennett JL, Cabre P, Carrol W, Chitnis T, et al. International consensus diagnostic criteria for neuromyelitis optica spectrum disorders. Neurology. 2015; 85:177-89.

11. Huisman TA, Wohlrab G, Nadal D, Boltshauser E, Martin E. Unusual presentations of neuroborreliosis (Lyme disease) in childhood. J Comput Assist Tomogr. 1999;23:39-42.

12. Blanc F, Froelich S, Vuillemet F, Carré S, Baldauf E, de Martino S, et al. Acute myelitis and Lyme disease. Rev Neurol. 2007;163:1039-47.

13. Blanc F, Jaulhac B, Fleury M, de Seze J, de Martino SJ, Remy V, et al. Relevance of the antibody index to diagnose Lyme neuroborreliosis among seropositive patients. Neurology. 2007;69:953-58.

14. Ljostad U, Skarpaas T, Mygland A. Clinical usefulness of intrathecal antibody testing in acute Lyme neuroborreliosis. Eur J Neurol. 2007;14:8736.

15. Rebman AW, Crowder LA, Kirkpatrick A, Aucott JN. Characteristics of seroconversion and implications for diagnosis of post-treatment Lyme disease syndrome: acute and convalescent serology among a prospective cohort of early Lyme disease patients. Clin Rheumatol. 2015;34:5859. 